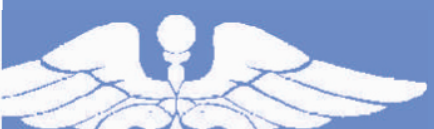

ISSN: 2782-7550 (Print) ISSN: 2782-7542 (Online)
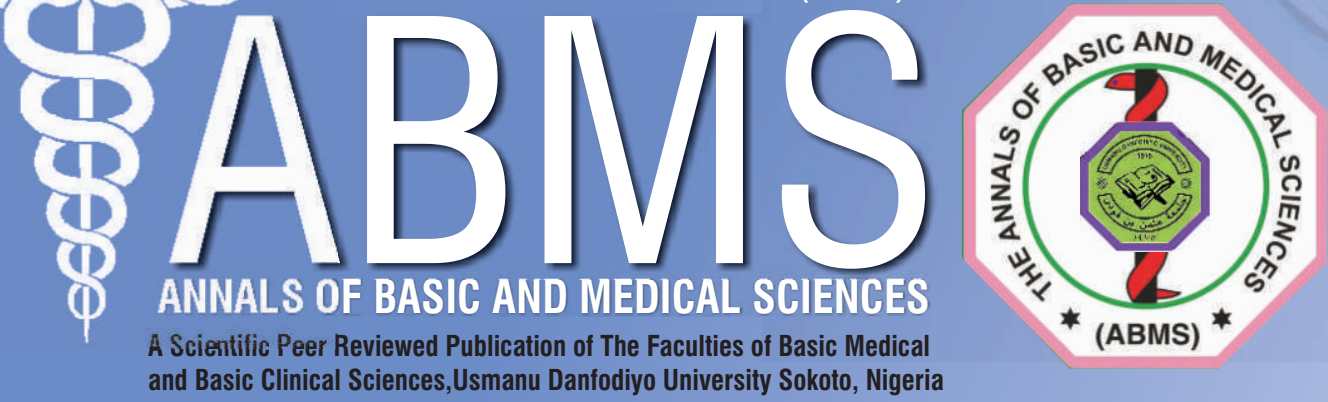

and Basic Clinical Sciences,Usmanu Danfodiyo University Sokoto, Nigeria
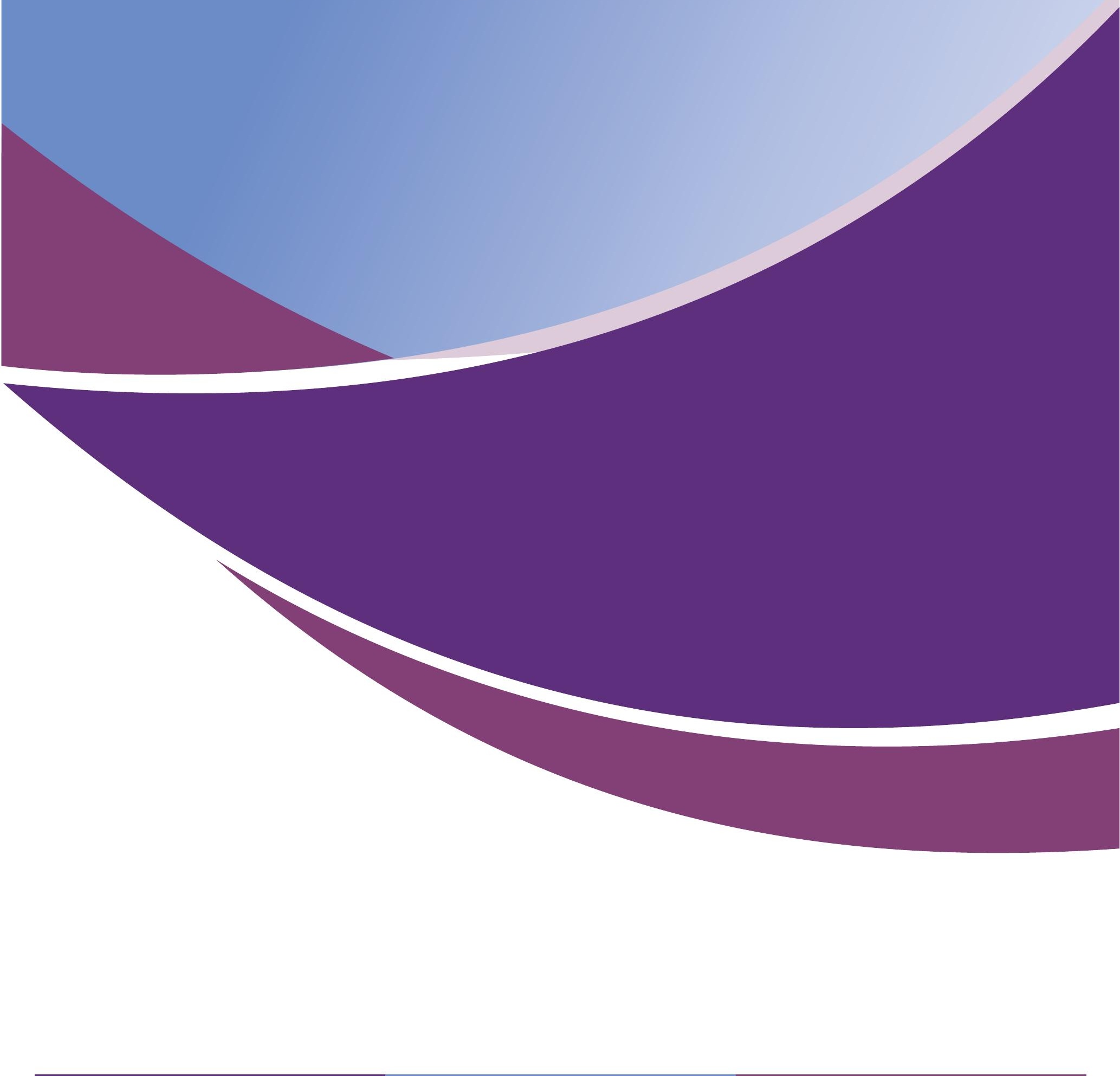

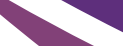
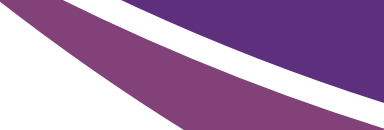


\title{
Prevalence of Hospital Associated Infections and Health Care Workers' Compliance with Hand Hygiene Practices in a Tertiary Hospital in Sokoto, Nigeria
}

\author{
Aminu U. Kaoje ${ }^{1}$, Yahaya Mohammed², Zainu M. Sabitu, Bilkisu G. Abubakar ${ }^{4}$, \\ Abdulrazaq M. Abduljabbar', Zubaidah B. Al-Hassan', Lawal Surajo', Auwal U. Abubakar, \\ Ismail A. Raji ${ }^{4}$, Abdulmumini Sa'ad ${ }^{1,5}$. \\ 1 Department of Community Health, Usmanu Danfodiyo University Sokoto, Nigeria \\ ${ }^{2}$ Department of Medical Microbiology and Parasitology, Usmanu Danfodiyo University Sokoto, Nigeria \\ ${ }^{3}$ Department of Medical Microbiology and Parasitology, Usmanu Danfodiyo University Teaching Hospital, Sokoto, Nigeria \\ ${ }^{4}$ Department of Community Medicine, Usmanu Danfodiyo University Teaching Hospital Sokoto, Nigeria \\ ${ }^{5}$ Independent Consultant/Medical Epidemiologist, Washington DC, USA
}

\begin{abstract}
Background: Hospital associated infections (HAls) remain a significant cause of morbidity and mortality. And despite the simplicity of hand hygiene practice, an important preventive measure that has been proven to reduce the risk of acquiring and transmitting HAls, Health care workers (HCW) compliance with the recommendations is of serious concern.

Aim: The aim of this study was to determine the prevalence of hospital associated infections and HCWs compliance with hand hygiene practice in a tertiary hospital.

Methods and material: This was a hospital-based descriptive cross-sectional study among 110 patients on admission selected using universal sampling, and $377 \mathrm{HCWs}$ selected using a multistage sampling technique. Data collected with self-administered questionnaire for HCWs, interviewer-administered proforma for the patients and data extraction sheet for laboratory analysis. Data analyzed for descriptive statistics using SPSS version 20.0 .

Results: Patients' mean age was 32.8, IQR: 10.5-37.9 years. Majority, 56(50.9\%) were females; Hausa/Fulani, 91(82.7\%) and 37(33.6\%) had only Qur'anic education while only $20(18.2 \%)$ had tertiary education. Health care workers' mean age was 31.85 .3 years. Majority $227(60.2 \%)$ are females, and $267(71.8 \%$ ) of the participants have received training on hospital infection control. Overall prevalence of HAls was $42.7 \%$, highest in surgical unit. Commonest HAls being blood stream infections, and the least, Health Care Associated Pneumonia. Most of the infections were due to Staphylococcus aureus, 22(46.8\%) and Pseudomonas aeruginosa, 14(29.8\%). Highest hand hygiene practice was reported after contact with body fluid and highest non-compliance reported was before touching patient. Hand hygiene compliance rate was $49.6 \%$ and main reasons to non-compliance were high work load, lack of running water and soap, and regular use of hand gloves.

Conclusions: Prevalence of HAls was reportedly high, and low hand hygiene compliance and rate despite majority of the HCWs having received training on Hospital infection control. To reduce the prevalence and the associated burden of HAls, there is need to put in measures to improve compliance to quality hand hygiene practice by health workers.
\end{abstract}

Keywords: Health care workers, Hospital Associated Infections, Hand hygiene.

Corresponding author:

Aminu Umar Kaoje

Department of Community Health Usmanu Danfodiyo University Sokoto, Nigeria,

Phone: +234-803-700-3110; e-mail: aukaoje@gmail.com
Introduction

$\mathrm{H}$ ospital associated infection (HAl) is an infection occurring in a patient during the course of care in the hospital or other health care facility, which hitherto not present or incubating at the time of admission (1). The infection can also develop after patient is discharged (2). Hospital Associated Infections represents the most frequent adverse event associated with patient care (3), and of substantial concern especially with regards to patient safety (4), and health care quality globally (5).

In developing countries, HAls burden is underreported or misclassified because expertise and resources required for complex diagnosis and surveillance activities is lacking (6). At any given time, the HAls prevalence varies between $3.5-12.0 \%$ in developed countries and $5.7-19.1 \%$ in low- and middle-income countries, with intensive care unit (ICU) acquired infections ranging from 4.4-88.9\% (7). World Health Organization (WHO), noted at any time, over 1.4 million people worldwide develop infectious complications associated with health care (8).

Hand hygiene with soap and water or alcohol-based hand rub remains the primary measure in reducing the risk or preventing HAls and enhancing patient safety $(9,10)$. Among patients and healthcare personnel, microorganisms are transmitted to others by indirect contact via staff hands because hand hygiene is neglected or performed inadequately (11). Hand hygiene, before and after all patient or patient environment contact, before a procedure, and after body-fluid exposure, are considered the standard of care for all Health care workers (HCWs) (12).

Studies have demonstrated association between HAls reduction and increased hand hygiene compliance rates (13-15). However, observation of many HCWs revealed that compliance remains alarmingly low. Hand hygiene compliance levels are considered 
excellent at $90 \%$ or higher (15). Studies conducted in Ethiopia, Ghana, Kuwait and India revealed an extremely low level of compliance at varying rates at $16.5 \%$ (16), $12 \%$ (17), 33.4\% (18), and $43.4 \%$ (19), respectively. In Europe, findings reveal differing compliance rates ranging from $33-65 \%(20-22)$. A study to assess HCWs' compliance with Hand hygiene practices in Istanbul revealed a compliance rate of $37.0 \%$ (23), while in Georgia reported compliance rate of $76 \%$, with varying rate along workers role ranging from $56-86 \%$ (24).

In as much as HCWs wish to comply with proper hand hygiene, it is employer's responsibility to ensure the commodities are readily available and accessible to all HCWs. A study in India revealed some of the barriers as inadequate hand hygiene supplies such as hand sanitizers, hand sinks, and towels, inconvenient placement of hand hygiene supplies, patients overcrowding, work overload and pressure, skin reaction to hand sanitizers, lack of awareness and old habit of not washing hands/forgetfulness (25).

Outbreak of infectious diseases is now a trigger of some attention HAls and good hand hygiene practices is receiving. On this context, this study is conducted with the aim to determine the prevalence of HAls and the compliance to hand hygiene practices among health care workers.

\section{Materials and methods}

The study was conducted in a tertiary hospital in Sokoto, North Western Nigeria between September and December 2019. It is a 900 bed capacity hospital with 24 clinical departments. The services provided include diagnostic, curative, preventive and rehabilitative services. The hospital has 20 wards and 52 clinics, with an average daily census of 930 patients and a monthly admission rate of 1,585 . The bed occupancy rate is $47.5 \%$ with an average hospital length of stay of 8 days. The facility staff strength is about 2000, of which 283 are doctors and 644 nurses.

A descriptive cross-sectional design was used to assess the Prevalence of Hospital Associated Infections and Compliance with Hand Hygiene Practices amongst the patients and Health Care Workers respectively. The study population comprised of all patients on admission and all doctors and nurses (here defined as health workers) in the selected tertiary hospital. The patients were recruited for the assessment of prevalence of hospital associated infection while the HCWs for the assessment of level of compliance with hand hygiene practices. The inclusion criteria for the patients, were having being on admission for at least 48 hours and must have developed new symptoms while on admission, or within 3 days of discharge and 30 days of surgical procedure. For health workers inclusion criteria include having been working in the hospital for at least three months, voluntary consent to participate and must be around during data collection. Sample size was determined using formula for descriptive studies,
$\mathrm{n}=Z a^{2} p q / d^{2}(26)$. For the patients, all those on admission and fulfilled criteria for inclusion into HAls arm of the study (spent at least 48 hours on admission, had no symptoms prior to admission, developeded new symptoms 48 hours after discharge) and consented to participate were enrolled. for the hand hygiene compliance arm of the study, the sample size formula was used and factoring for sample adjustment/correction factor due to non-response or loss of part/whole of the filled questionnaire, a sample size of 377 was obtained for HCWs. For patients, universal sampling was used where all the eligible patients on admission were enrolled. For the HCWs, a multi-stage sampling method was used to select the respondents. Stage 1: Selection of Departments: Four departments were randomly selected using simple random sampling by balloting. Stage 2: Proportionate allocation of the number of respondents to be recruited from each Department was done using the calculated sample size. Stage 3: Using a simple random sampling technique by balloting, the respondents were selected from each of the Departments until the allocated number was obtained. An interviewer-administered questionnaires were administered to patients, self-administered questionnaires HCWs, while data extraction sheet was used to retrieve laboratory results from the participating patients' case note. Research assistants were engaged and trained on the conduct of the research, including interpersonal communication skills. Data collection tools were pretested among $10 \%$ (38) health care workers and 20 eligible patients in a different tertiary hospital. Data cleaning was done manually for completeness and errors on the questionnaires. This was followed by using IBM® SPSS software paltformversion 20.0. Continuous data were summarized using mean and standard deviation, while categorical data were summarized using frequencies, percentages. Hand hygiene compliance rate was calculated for HCWs and categorized as compliant and non compliant. Compliance rate to hand hygiene by HCWs of $90 \%$ or above is said to compliant and less than $90 \%$ is said to non-compliance. Results were presented in tables and chart.

Ethical approval was obtained from the Hospital Research Ethics Committee and consent obtained from individual study participants prior to questionnaire administration.

\section{Results:}

Patients' average age was 32.8, IQR: 10.5-37.9 years. Majority, 56(50.9\%) were females; Hausa/Fulani ethnic group, $91(82.7 \%)$ and $37(33.6 \%)$ had only Qur'anic education while only $20(18.2 \%)$ had tertiary education. Table 1

Out of 210 patients on admission, only $110(52.4 \%)$ fulfilled criteria for inclusion in the study. Overall HAls prevalence in the study centre was $42.7 \%$ (95\% Cl:33.852.1). Disaggregation by settings revealed a prevalence of $50.0 \%$ in paediatric units, $47.7 \%$ in surgical unit, $34.5 \%$ 
in medical unit and $33.3 \%$ each in Gynae ward and ICU. The most prevalent HAls was Bloodstream infections, 20(42.6\%) while the least prevalent was Health Care Associated Pneumonia (HCAP), 5(0.6\%). Almost half $22(46.8 \%)$ of the infections were due to Staphylococcus aureus, Pseudomonas aeruginosa accounted for 14 (29.8\%) and the less common organism were Klebsiella spp. Table 2.

Table 1. Sociodemographic Characteristics of the Patients

\begin{tabular}{lll}
\hline Variable & Number $(\mathbf{n}=\mathbf{1 1 0})$ & Percentage \\
\hline Age (years) & 28 & \\
$1-10$ & 19 & 25.5 \\
$11-20$ & 16 & 17.3 \\
$21-30$ & 21 & 14.5 \\
$31-40$ & 26 & 19.1 \\
$\geq 41$ & & 23.6 \\
Sex & 54 & 49.1 \\
Male & 56 & 50.9 \\
Females & & \\
Ethnic group & 91 & 82.7 \\
Hausa/Fulani & 12 & 10.9 \\
Others & 4 & 3.6 \\
Yoruba & 3 & 2.8 \\
Igbo & & \\
Educational level & 37 & 33.6 \\
Qur'anic & 25 & 22.7 \\
Primary & 28 & 25.5 \\
Secondary & 20 & 18.2 \\
Tertiary & & \\
\hline
\end{tabular}

Table 2. Prevalence and Distribution of HAls by settings, types and pathogens

\begin{tabular}{|c|c|c|c|}
\hline Types of HAls & No. fuffilled HAl criteria & No. of patient swith HAls & Percentage \\
\hline Overall prevalenoe & 110 & 47 & 427 \\
\hline \multicolumn{4}{|l|}{ HAls by hospital setting: } \\
\hline Paediatric Unit & 22 & 11 & 50.0 \\
\hline Paedaticics wards & 12 & 6 & 50.0 \\
\hline Special care baby unit & 10 & 5 & 50.0 \\
\hline Srgical Unit & 44 & 21 & 47.7 \\
\hline Urology ward & 12 & 6 & 50.0 \\
\hline Neurosurgeny ward & 8 & 4 & 50.0 \\
\hline Fem ale surgical & 8 & 4 & 50.0 \\
\hline Paediatric Srgical ward & 8 & 4 & 50.0 \\
\hline Male surgical & 8 & 3 & 37.5 \\
\hline Medical Unit & 29 & 10 & 34.5 \\
\hline Nalemedical & 15 & 5 & 33.3 \\
\hline Fenalemedical & 14 & 5 & 35.7 \\
\hline Gynae Unit & 12 & 4 & 33.3 \\
\hline ia & 3 & 1 & 33.3 \\
\hline \multicolumn{4}{|l|}{ HAlsbytypes * } \\
\hline Blood streaminfections & & 20 & 426 \\
\hline Catheter associatedUTls & & 15 & 31.9 \\
\hline Surgical site infections (SSIS) & & 13 & 27.7 \\
\hline Heath Care Associated Phem monia & (HCAP) & 5 & 10.6 \\
\hline \multicolumn{4}{|l|}{ HAs by Causative argarisms ～* } \\
\hline Staphylococous aureus & & 22 & 46.8 \\
\hline Psendomonas aruginosa & & 14 & 29.8 \\
\hline Streptococous pneumanize & & 11 & 23.4 \\
\hline Escherichia a oli & & 4 & 8.5 \\
\hline Kebsiellaspo. & & 3 & 6.4 \\
\hline
\end{tabular}

*multiple responses allowed

Of the five patients that had previous history of positive culture, four were positive for ESBL and one for MRSA. Most $44(93.6 \%)$ of the patients with HAls have indwelling urinary catheter and 20 (42.6\%) each had a nasogastric tube, arterial lines and ventilator use. Slightly above three-quarters $36(76.6 \%)$ had used Ciprofloxacin, $33(70.2 \%)$ used Ceftriaxone and about a half, 22 (46.8\%) used Amoxicillin-clavulanic acid. Most $39(83.0 \%)$ had a prior history of hospital admission, and the majority, $30(63.8 \%)$ had surgery within the last three months. A little above a quarter of the patients, $13(27.7 \%)$ have decubitus ulcer while HIV/AIDS and his- history of recent haemodialysis were the least reported co-morbidities. Table 3.

Table 3. Respondents' Past Medical and Co-Morbidities History $(n=47)$

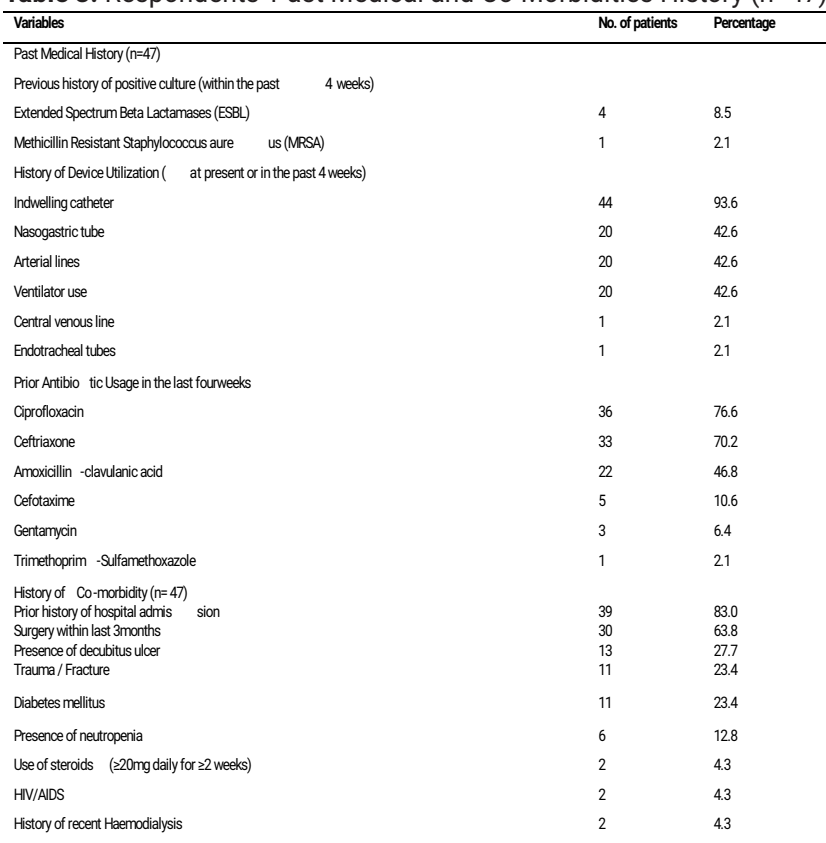

Health workers' overall mean age was 31.85 .3 years. Slightly above half, $192(52.0 \%)$ of the respondents were in the 25-39 years age group. Majority, 227(60.2\%) were females, Hausa 200(53.1\%), Muslims 240(64.0\%), while 262(69.5\%) were married. Majority, 230(61.2\%) had less than five years of work experience and about three-quarters had received training on hospital infecti on control. Table 4.

Table 4: Socio-Demographic and work-related characteristics of the Health workers

\begin{tabular}{|c|c|c|c|}
\hline \multicolumn{2}{|l|}{$\begin{array}{l}\text { Variables } \\
\end{array}$} & Number & $\begin{array}{l}\text { Percentage } \\
\end{array}$ \\
\hline \multicolumn{2}{|l|}{$\begin{array}{ll}\text { Age (vears) } \\
10.92\end{array}$} & & \\
\hline & 82 & \\
\hline \multirow{2}{*}{\multicolumn{2}{|c|}{240}} & 196 & \\
\hline & & 99 & 26.2 \\
\hline & 150 & 39.8 \\
\hline \multirow{2}{*}{\multicolumn{2}{|c|}{ Females }} & 227 & 60.2 \\
\hline \multirow{2}{*}{\multicolumn{2}{|c|}{ Hausa }} & & \\
\hline & & 200 & 53.1 \\
\hline \multirow{2}{*}{\multicolumn{2}{|c|}{ Yoruba }} & 110 & 29.2 \\
\hline & & 40 & 10.6 \\
\hline \multicolumn{2}{|l|}{ Religion(n=375) } & 27 & 7.2 \\
\hline \multirow{2}{*}{\multicolumn{2}{|c|}{$\begin{array}{l}\text { Muslim } \\
\text { Chiscion }\end{array}$}} & 240 & 64.0 \\
\hline & & 129 & 34.4 \\
\hline \multicolumn{2}{|l|}{ Others } & 6 & 1.6 \\
\hline \multicolumn{2}{|l|}{$\begin{array}{l}\text { Natrallataus } \\
\text { Naried }\end{array}$} & 266 & 695 \\
\hline \multirow{2}{*}{\multicolumn{2}{|c|}{ Single }} & & \\
\hline & & 4 & 1.1 \\
\hline \multirow{2}{*}{\multicolumn{2}{|c|}{$\begin{array}{l}\text { Wocow } \\
\text { Occupation }\end{array}$}} & 4 & 1.1 \\
\hline & & & \\
\hline & 100 & 26.5 \\
\hline \multirow{2}{*}{\multicolumn{2}{|c|}{$\begin{array}{l}\text { Nurses/Mdwives } \\
\text { Years of Sevice in the hospital (n-376) }\end{array}$}} & $2 \pi$ & 73.5 \\
\hline \multirow{2}{*}{\multicolumn{2}{|c|}{$<1$}} & 100 & 26.6 \\
\hline & & 130 & 34.6 \\
\hline \multicolumn{2}{|l|}{$\begin{array}{l}1-4 \\
5-9\end{array}$} & 90 & 23.9 \\
\hline \multirow{2}{*}{\multicolumn{2}{|c|}{$\begin{array}{l}\text { Training Received on Hospital Infection Control( }(n-372) \\
\text { No } \\
\text { Yes }\end{array}$}} & 56 & \\
\hline & & 105 & 28.2 \\
\hline
\end{tabular}

Highest hand hygiene practice were reported for after contact with body fluid, (52.5\%), while the highest non compliance was reported for hand hygiene before touching patient, $(85.1 \%)$, followed by after removing hand gloves by $66.0 \%$. Figure 1 . 


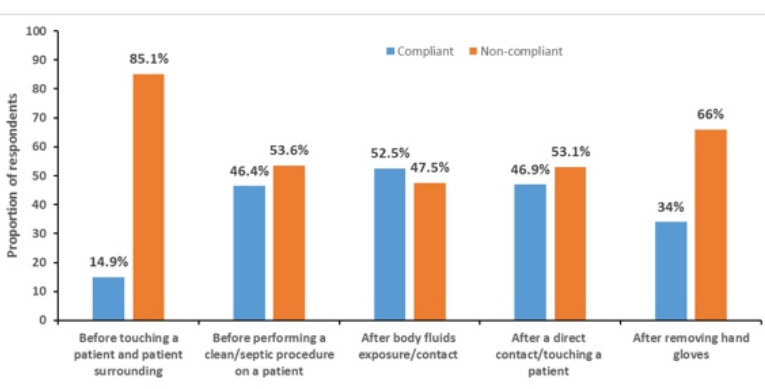

Figure 1: Assessment of Hand Hygiene Practices

Overall hand hygiene compliance rate was $49.6 \%$ (95\% $\mathrm{Cl}: 48.9-50.3)$. Disaggregation by hand hygiene opportunities revealed compliance rate of $84.6 \%$ after body fluids exposure, followed by before performing a procedure on a patient, $82.6 \%$. The lowest compliance rates of $21.0 \%$ was reported for before touching a patient and patient surrounding. Table 5 .

Table 5: Hand Hygiene Opportunities and Compliance Rate among HCWs

\begin{tabular}{|c|c|c|c|}
\hline Characteristics & $\begin{array}{l}\text { No. of Hand hygiene } \\
\text { Opportunities }\end{array}$ & $\begin{array}{l}\text { No. of hand } \\
\text { hygiene } \\
\text { perform }\end{array}$ & $\begin{array}{l}\text { Compliance rate } \\
\text { (\%) }\end{array}$ \\
\hline Before touching a patient and patient surrounding & 5979 & 1257 & 21.0 \\
\hline Before eefforming a procedure (dear/aseptic) on a patient & 2568 & 2120 & 826 \\
\hline After body fluids exposure or contact & 2047 & 1731 & 84.6 \\
\hline After direct contact/touching a patient & 3688 & 1461 & 39.6 \\
\hline After removing hand gloves & 3332 & 2167 & 65.0 \\
\hline Verelll compliance rate & 17,614 & 8,736 & 49.6 \\
\hline
\end{tabular}

Most cited barrier was high workload by $88(23.3 \%)$ of the respondents, closely followed by lack of running water and soap, $80(21.2 \%)$, and regular use of hand gloves $79(21.0 \%)$ and lack of alcohol-based hand rub 77(20.4\%). Table 6.

Table 6: Barriers to routine hand hygiene performance

\begin{tabular}{|c|c|c|}
\hline Variables & Frequency & Percentage \\
\hline High workload (often too busy) & 88 & \\
\hline Lack of running tap water and soap & 80 & 21.2 \\
\hline I always wear hand gloves, so no need for hand hygiene & 79 & 21.0 \\
\hline Lack of alcohol -based hand rub & 77 & 20.4 \\
\hline Lack of enforcement by the hospital management & 71 & 18.8 \\
\hline 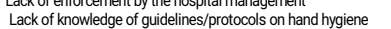 & 61 & 16.2 \\
\hline Lack of hospital priority for hand hygiene & 53 & 14.1 \\
\hline Lack of displayed $\forall H$ poster at paint of care for remembrance & 52 & 138 \\
\hline 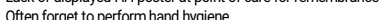 & 52 & 138 \\
\hline ow risk of acourinini infection from antients. & 5 & 135 \\
\hline Lack of administrative sanction of non -compliers & 39 & 10.3 \\
\hline Sceptic about the value of hand hygiene practices & 37 & 9.8 \\
\hline $\begin{array}{l}\text { Hand hygiene agents affect patients } \\
\text { Horleres }\end{array}$ & 35 & 9.6 \\
\hline My teachers or superiors don't do hand washing or rubbing & 33 & 8.8 \\
\hline 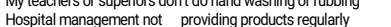 & 32 & 8.5 \\
\hline Hond washing agents cause irritation \& dryness of $t$ he skin & 20 & 5.3 \\
\hline Lack of knowledge, experience and education & 6 & 1.6 \\
\hline
\end{tabular}

Multiple responses allowed

\section{Discussion}

This study aimed to determine the prevalence of hospital associated infections and health workers compliance to hand hygiene performance in a tertiary hospital.The study revealed a point prevalence of HAls, which was also found to differ by hospital settings and health workers role. This very high prevalence rate depicts the unpleasant situation of infection prevention and control practices. Every one of two patients admitted to paediatric and surgical units developed HAls making these places the most dangerous place for the patient to be in respect to safety and quality of care. Although not all HAls are preventable, majority of the infection can be prevented if there is excellent adherence to hospital infection prevention and control guidelines by health workers largely and patients themselves. The low compliance rate to hand hygiene in this study may largely be responsible for the high HAI prevalence. The patients' medical characteristics may have also partly contributed to this very high rate. It was observed that all the patients had a history of co-morbidities and device utilization such as an indwelling urinary catheter and nasogastric tube. Many others also had prior history of hospital admission, surgeries within the last three months and antibiotic use, many of which are very likely to be self-prescribed. Loss of efficacy of disinfectants from overdilution by hospital cleaners and or substandard disinfectants may not be ruled out as also a possible risk factor for the reported HAI prevalence. More than a third of the HAls were Bloodstream and Catheter associated Urinary Tract Infections mostly due to Staphylococcus aureus and Pseudomonas aeruginosa. Device use such as intravenous line and urethral catheter on patient is common practice in this setting. Nearly every patient on admission must have intravenous line for rehydration and intravenous drug administration. A study conducted in eight university hospitals of Iran reported an overall HAI prevalence of $9.4 \%$ with the most common HAls being bloodstream infections, SSIs, UTIs, and pneumonia (27). A study in Singapore reported $11.9 \%$ mainly caused by $S$.aureus and Pseudomonas aeruginosa (28). Studies on HAI from Southeast Asian countries found an overall prevalence rate of $9.1 \%$ with the most common microorganisms being $P$. aeruginosa, the Klebsiellaspecies, and Acinetobacter baumannii (29). In contrast, a study from Florida, USA revealed that Staphylococcus aureus was the most frequently detected microorganism among HAl patients (30). Staphylococcus aureus being the normal flora organism and asymptomatically carried in nostril of significant proportion of population, easily become a culprit.

Health workers hand are germ farm and therefore are a viable vehicle for cross-transmission of infectious agents. Although HCWs are expected to practice good hand hygiene to remove visible soiling from hands, to prevent the transfer of bacteria from the home to the hospital, to prevent transfer of bacteria from the hospital to the home, single most important reason is to prevent infections that patients acquire in the hospital called hospital associated infections (HAls). The overall hand hygiene compliance rate in the study setting was found to be $49.6 \%$, and this was also found to differ across the WHO 'My five moments of hand hygiene'. It was highest after body fluids exposure or contact/risk and before performing a procedure(clean/aseptic) on a patient. Very few respondents reported performing hand washing/decontamination across the 'five mo ments' always, as a substantial number rarely or never 
perform. The study finding is not comparable with recommended $90 \%$ or higher considered excellent for hand hygiene compliance rate required to achieve a predictable risk reduction in infection rate (15).

Studies conducted in Ethiopia, Ghana, Kuwait and Indian, revealed an extremely low level of compliance at varying rates of $16.5 \%$ (16), 12\% (17), 33.4\% (18), and $43.4 \%$ (19), respectively. Similarly, a low compliance rate of $37 \%$ was reported from a study in Istanbul (23). Also, reports from studies in Europe revealed differing hand hygiene compliance rates ranging from 33 to $65 \%$ (20-22). Similarly, in Georgia, the compliance rate of approximately $76 \%$, was reported though with varying rate along workers role ranging from $56 \%$ to $86 \%$ (24). Although all reports from the different studies were substantially below the compliance level considered excellent, the finding were worse in low- to middleincome countries. The variations could be attributed to a low commitment by health care managers and lack of adequate resources towards infection control practices. In as much resources committed will continue to be negligible, the HAls will remain endemic and the associated burden will continue to rise and compromise patient safety and quality of care. If not properly handled particularly in developing countries, it is likely to lead to a level of public health emergency of international concern. This poor compliance to hand hygiene by HCWs is likely to facilitate cross-transmission of infection among patients in the hospital as the world is faced with COVID 19 pandemic. Compliance to hand hygiene with soap and water or alcohol-based hand rub is only second to social and physical distancing approach to breaking the chain of local and community transmission.

Many reasons hand hygiene practice is not adhered to were reported, and most self-reported for poor compliance were high workload, lack of running water and soap, regular use of hand gloves and lack of alcoholbased hand rub. Among other duties and responsibilities of health care managers as an employer is to ensure the availability and accessibility of hand hygiene commodities to all categories of health workforce at all times. In the Leggs aphorism, it was stated 'Unless and until the employer has done everything-and everything means a good deal-the workman can do next to nothing to protect himself although he is naturally willing enough to do his bit (31).

A study revealed some of the reasons as inadequate hand hygiene supplies such as hand sanitizers, hand sinks, and towels, Inconvenient placement of hand hygiene supplies, patients overcrowding, Work overload and pressure, skin reaction to hand sanitizers, lack of awareness and old habit of not washing hands/forgetfulness (25). A study among health care workers in a public hospital in Kano, reported multiple constraints to hand hygiene the majors being lack of water and/or lack of soap, as well as lack of alcohol hand rub. Other constraints included not knowing how to wash hands, no place provided for washing hands, no time to wash hands while at work, and not remembering to wash hands while at work (32). A study from Southern Nigeria, reported lack of hand hygiene facilities such as clean towels, hand lubricants, running water, soap, water sinks not conveniently placed as barriers to complying regular hand hygiene (33). While some provider reported anticipated difficulties in ensuring regular hand hygiene even if the facilities are available because of lack of time, heavy patients traffic, non- conducive atmosphere, and forgetfulness (17). Another study from India revealed hand hygiene Barriers as inconvenient placement of Hand hygiene facility, overburden of patient care, forgetfulness, Sore hands/abrasions on hands, Hand hygiene unnecessary when gloves are worn, belief of low risk of acquiring infection from patients, among others (34). These barriers are cross-cutting and overcoming most of them is sole duties and responsibilities of the employer. As long as these barriers continue to prevail, the hand hygiene practice will be unimplementable, thereby increasing the HAls with their associated burdens.

The limitation is that self-reported information were used. This form of data gathering could be prone to bias by overestimating their adherence to hand washing rules. There is also likelihood to inaccurately recall their past Hand Hygiene behaviour including number of opportunities to perform hand.

In conclusion, Hospital Associated infections remains high as evidenced by high prevalence in different hospital settings. The hospital management should ensure continuous availability and accessibility of hand hygiene commodities to all. There is also need to strengthen the infection prevention activities and ensure regular environmental surveillance and risk assessment. Further researches are required to the role of HCWs uniform cross-transmission of microorganism and also assess the efficacy of different cleaning solution used in hospital disinfection.

\section{Acknowledgement:}

We acknowledged the cooperation of the Management of the Hospital for granting permission for the smooth conduct of the study. So also the study participants for their valuable time and information provided.

\section{References}

1. World Health Organization Guidelines on hand hygiene in health context WHO. 2009. Last update 4/3/2010.

2. World Health Organization Alcohol-based hand rub planning and costing tool. 2010. Last update 8/10/2011.

3. WHO guidelines on hand hygiene in health care in context of Filovirus disease outcome response. 2010. Last update1/12/2016.

4. Allegranzi B, Bagheri NS, Combescure C, Graafmans W, Attar H, Donaldson $L$, et al. Burden of endemic health-care-associated infection in developing countries: Systematic review and metaanalysis. Lancet 2011, 377; 228-241.

5. Anthony S, Fauci E, and David M. The Perpetual Challenge of Infectious Disease. The New England Journal of Medicine. 2012; 31:21-24.

6. Mohammed A, Aliyu I, and Godpower M. Hand Washing Practices 
and Techniques among health professionals in a tertiary hospital in Kano. Journal of Medical Investigations and Practice 2015; 10:8-12.

7. Margret $\mathrm{H}$, and Francis $\mathrm{E}$. The French prevalence study group: prevalence of nosocomial infection in France, Journal of Hospital Infection.2016;10:16-18.

8. Vicki E, Thea JD, Hans B, Richardus JH, Behrendt MD, Vos MCet al. Systemic review of studies on compliance with hand hygiene guidelines in hospital care. American Journal of Public Health. 2010; 31:3.

9. Segun, Bello \& Effa, Emmanuel \& Okokon, Enembe \& Oduwole, Olabisi \& Bello, Segun. (2013). Handwashing practice among healthcare providers in a teaching hospital in Southern Nigeria. International Journal of Infection Control. 9. 10.3396/IJIC.v9i4. 031.13.

10. Grayson M, Menvani F, and Druse E. Efficacy of soap and water versus alcohol-based hand rub preparation against Influenza virus. 2016. Last update 5/7/2013

11. Askarian $M$, Yadollahi $M$, Assadian O. Point prevalence and risk factors of hospital acquired infections in a cluster of universityaffiliated hospitals in Shiraz, Iran. J Infect Public Health. 2012; 5(2):169-176.

12. Public Health Ontario, Just Clean Your Hands-Your 4 Moments for Hand Hygiene, Public Health Ontario, Ontario Agency for Health Protection and Promotion, 2011.

13. Morgan, Daniel \& Pineles, Lisa \& Shardell, Michelle \& Young, Atlisa \& Ellingson, Katherine \& Jernigan, John \& Day, Hannah \& Thom, Kerri \& Harris, Anthony \& Perencevich, Eli. (2012). Automated hand hygiene count devices may better measure compliance than human observation. American journal of infection control. 40. 10.1016/j.ajic.2012.01.026

14. Kirkland KB, Homa KA, Lasky RA, Ptak JA, Taylor EA, Splaine ME. Impact of a hospital-wide hand hygiene initiative on healthcareassociated infections: results of an interrupted time series. BMJ Qual Saf. 2012 Dec;21(12):1019-26. doi: 10.1136/bmjqs-2012000800. Epub 2012 Jul 21. PMID: 22822243.

15. World Health Organization (WHO) Evidence of hand hygiene to reduce transmission and infections by multi-drug resistant organisms in healthcare settings. World Health Organization. 2014. Available at: http://www.who.int/gpsc/5may/MDRO

16. Nura MA, Mekuriaw AT, Timoth FL, Yewunete D M and Kefyalew AA. Hand hygiene compliance and associated factors among health care providers in Gondar University Hospital, Gondar, North West Ethiopia. BMC Public Health. 2014, volume 14, Article number: 96

17. Owusu-Ofori A, Jennings R, Burgess J, Prasad PA, Acheampong F, Coffin SE. Assessing hand hygiene resources and compliances at a large African teaching hospital. Infect Control Hosp Epidemiol. 2010, 31 (8): 802-808. 10.1086/654005.

18. Al-Wazzan B, Salmeen Y, Al-Amiri E, Abul A, Bouhaimed M, Al-Taiar $A$ : Hand hygiene compliance s among nursing staff in public secondary care hospitals in Kuwait: self-report and direct observation. Med Princ Compliance. 2011, 20 (4): 326-331. 10.1159 1000324545 .

19. Sharma S, Sharma S, Puri S, Whig J: Hand hygiene compliance in the intensive care units of a tertiary care hospital. Indian J Community Med. 2011, 36 (3): 217-221. 10.4103/0970-0218. 86524.
20. Kouni S, Kourlaba G, Mougkou K, Maroudi S, Chavela B, Nteli C et al. Assessment of hand hygiene practices at the two children's hospitals in Greece," Antimicrobial Resistance and Infection Control, vol. 2, supplement 1, article P130, 2013, Proceedings of the 2nd International Conference on Prevention and Infection Control, Geneva, Switzerland, June 2013.

21. Helder OK, Van Goudoever JB, Hop WCJ, Brug J, and Kornelisse RF. "Hand disinfection in a neonatal intensive care unit: continuous electronic monitoring over a one-year period," BMC Infectious Diseases. 2012; vol. 12, article 248.

22. Schwadtke L, Graf K, Lutze B, Von Lengerke T, and Chaberny IF. "Compliance with hand hygiene guidelines on intensive care units at a university medical centre with surgical focus," Deutsche medizinische Wochenschrift. 2014; vol. 139, no. 25-26, pp.13411345

23. Ayse K, Eda KK, Serkan A, Uluhan S, Ahmet S, Gulcan C, et al. Compliance of Healthcare Workers with Hand Hygiene Practices in Neonatal and Pediatric Intensive Care Units: Overt Observation Interdisciplinary Perspectives on Infectious Diseases. 2014; Article ID 306478

24. Monteiro A. "Evaluating Hand Hygiene Compliance Among Health care Workers in a Specialized Pediatric Hospital." Thesis, Georgia State University, 2018

25. Cam DL, Erik BL, Thanh HN, Timothy JC. Hand Hygiene Comp liance Study at a Large Central Hospital in Vietnam. Int. J. Environ. Res. Public Health. 2019, Vol. 16: 607; doi:10.3390/ijerph16040607

26. Ibrahim T. Research Methodology and dissertation writing for the health and allied health professionals. Abuja: Cress Global links Itd; 2009.

27. Askarian M, Yadollahi M, Assadian O. Point prevalence and risk factors of hospital acquired infections in a cluster of universityaffiliated hospitals in Shiraz, Iran. J Infect Public Health. 2012;5 (2):169-176

28. Cai Y, Venkatachalam I, Tee NW, et al. Prevalence of HealthcareAssociated Infections and Antimicrobial Use Among Adult Inpatients in Singapore Acute-Care Hospitals: Results From the First National Point Prevalence Survey. Clin Infect Dis. 2017;64 (Suppl 2):S61-S67.

29. Ling ML, Apisarnthanarak A, Madriaga G. The Burden of Health care-Associated Infections in Southeast Asia: A Systematic Literature Review and Meta-analysis. Clin Infect Dis. 2015;60(11): 1690-1699.

30. Magill SS, Hellinger W, Cohen J, et al. Prevalence of HealthcareAssociated Infections in Acute Care Hospitals in Jacksonville, Florida. Infect Control Hosp Epidemiol. 2012;3(3):283-291.

31. Proceedings of the XIVth International Congress of Occupational Health. 1964. Page 228

32. Gwarzo GD. Hand Hygiene practice among healthcare workers in a public hospital in North-western Nigeria. Niger J Basic Clin Sci. 2018; 15: 109-13.

33. Segun B, Emmanuel E, O Enembe O. A hand washing practice among health providers in a teaching hospital in southern Nigeria. Int J Infect Control. 2013:1-7.

34. Kumar G, Puneet S, Purnima K, Ravneet RV, Renu S, Richa RS Hand Hygiene, Attitude and Barriers among Health Care Workers at a Tertiary Care Teaching Hospital, Uttarakhand. 2017; 10.13140/ RG.2.2.34225.63849. 